\title{
A EDUCAÇÃO COMEÇA NO VENTRE E A DEMOCRACIA NO COLO DA MÃE
}

\author{
Maria José Rocha Lima ${ }^{1}$
}

\begin{abstract}
RESUMO
Este trabalho reúne as decisões mais recentes que ocorreram no Brasil para definir a legislação, políticas e programas em favor da primeira infância. Na introdução, foi feita uma revisão dos argumentos e evidências resultantes de diversas ciências, que sustentam a importância e reorientação das políticas para a Educação Infantil e na primeira infância. Na primeira parte, foi apresentada a evolução das medidas legislativas aprovadas no Brasil, para aplicação na política de Educação Infantil, na primeira infância, ressaltando os avanços e perspectivas. Na segunda parte, foram descritas as evidências científicas, fruto de estudos divulgados pelo Comitê Científico do Núcleo Ciência Pela Infância, da Universidade de Harvard (2015), sobre o Impacto do Desenvolvimento na Primeira Infância para a Aprendizagem. Além dos estudos do cientista James Heckman, vencedor do Prêmio Nobel de Economia no ano 2000, que realizou uma das experiências de maior repercussão mundial nessa temática. $\mathrm{Na}$ terceira parte, demos voz ao cientista Zeljko Loparic, maior especialista brasileiro nos estudos da obra do pediatra e psicanalista inglês Donald Woods Winnicott, na qual apresenta evidências de que as relações sociais começam na maternagem, na relação mãe-bebê. Conclui analisando os compromissos estabelecidos pelo governo brasileiro na aplicação das políticas pela primeira infância para a superação das desigualdades sociais.
\end{abstract}

Palavras-chave: Primeira Infância. Educação Infantil. Legislação. Políticas Públicas. Democracia.

\section{INTRODUÇÃO}

No Brasil, é absolutamente inédita e recente a política de educação infantil influenciada por evidências científicas resultantes das pesquisas sobre crianças pequenas em várias áreas das ciências humanas, sociais, médicas e, particularmente, nas mais recentes descobertas no campo da neurociência. Estas descobertas das ciências sobre o desenvolvimento infantil na Primeira Infância constituem uma das razões mais eloquentes para a defesa da educação infantil como direito fundamental. Nessa fase da Primeira Infância, observou-se que o desenvolvimento cerebral é intenso; é possível estabelecer até 700 novas conexões neuronais por segundo, praticamente o dobro de sinapses executadas aos dez anos de idade, de acordo com estudos feitos pela Academia Nacional de Ciências dos Estados Unidos (2015).

Estudo divulgado pelo Comitê Científico do Núcleo Ciência Pela Infância, da Universidade de Harvard (2015), sobre o Impacto do Desenvolvimento na Primeira Infância para a Aprendizagem, mostra que nesse período as funções cognitivas mais especializadas como atenção, memória, planejamento, raciocínio e juízo crítico começam a se desenvolver na

\footnotetext{
${ }^{1}$ Mestre em Educação pela Universidade Federal da Bahia (UFBA). E-mail: zezerochalima@ hotmail.com
} 
primeira infância por meio de habilidades, como controle de impulsos, a capacidade de redirecionar atenção e de lembrar regras. Os estudos apontam, ainda, impressionantes mudanças que ocorrem nos primeiros cinco a seis anos de vida dos seres humanos, que incapazes de falar, locomover-se e organizar-se, ao se relacionar com o mundo ao redor, de maneira construtiva, receptiva e positiva, passam a mover-se, comunicar-se através de várias linguagens, criando, transformando e afetando suas próprias circunstâncias de interação com pessoas, eventos e lugares.

Nunca deveríamos ter negligenciado a atenção e educação do bebê na Primeira Infância, uma vez que pelas próprias características biológicas, o bebê humano nasce inacabado e estruturado para aprender, portanto dependente do outro para a sua sobrevivência física e psíquica. A educação para o homo sapiens é uma imposição porque somos biologicamente sociais, dependentes do outro ao nascer e nos caracterizamos por possuir duas aptidões estupendas, que são a plasticidade do cérebro e a aptidão para aprender. Por tudo isto, a educação na Primeira Infância deve ser positivada como um Direito Fundamental, que não dependa da vontade de agentes públicos de plantão.

\section{PRIMEIRA INFÂNCIA NA LEI: AVANÇOS E PERSPECTIVAS}

$\mathrm{O}$ atendimento institucional à criança pequena apresentou, no decorrer da história, concepções bastante divergentes sobre a sua função social. A maioria dessas instituições de atendimento nasceu com a finalidade de atender exclusivamente às crianças pobres.

As creches e programas de pré-escolas sempre constituíram instituições estratégicas para enfrentamento da pobreza e resolver os problemas das crianças em contextos de vulnerabilidades, o que justificava em grande medida o baixo investimento, com a destinação de recursos orçamentários, quase sempre, irrisórios; em instalações precárias; sem exigência de profissionais qualificados e com um número muito desproporcional de crianças, sob a responsabilidade de poucos adultos.

Entre as estratégias para justificar a educação pré-escolar estava aquela de educação compensatória, para reduzir os altos índices de evasão e repetências das crianças pobres ao ingressarem no ensino fundamental.

O estabelecimento de uma política nacional para a infância ainda é bem recente no Brasil, como um investimento social que considera as crianças como sujeitos de direitos, cidadãs em processo de desenvolvimento. Uma política nacional, que se remete à indispensável integração do estado e da sociedade civil, como coparticipantes das famílias no cuidado e 
educação de seus filhos entre 0 a 6 anos. Embora os intelectuais que subscreveram o Manifesto dos Pioneiros da Educação Nova de 1932, dentre eles Anísio Teixeira, já defendessem claramente a educação infantil como uma etapa da educação, isto só se positivou na Constituição de 1988, que foi considerada um marco na conquista de vitórias importantes para a garantia de direitos para a população infanto-juvenil e, posteriormente, consolidadas no Estatuto da Criança e do Adolescente.

Em 1996, a Lei de Diretrizes Básicas da Educação (LDB) estabeleceu a educação infantil como a primeira etapa da educação básica² .

Em 2006, registra-se a maior das conquistas das últimas décadas, senão da história, da educação infantil, com a aprovação da Emenda Constitucional n ${ }^{\circ} 53$, que criou o Fundo de Manutenção e Desenvolvimento da Educação Básica e de Valorização dos Profissionais da Educação (FUNDEB) e, em seu art. $7^{\circ}$, inciso XXV, estabelece a assistência gratuita aos filhos e dependentes desde o nascimento até cinco anos de idade em creches e pré-escolas, e no Art. 208, inciso IV, assegurando a oferta da educação infantil, em creche e pré-escola, às crianças até 5 (cinco) anos de idade, oferta que se tornou obrigatória para crianças de 4 e 5 anos, desde 2016.

Em 2009, ocorreu mais uma importante conquista a aprovação da Emenda Constitucional $\mathrm{n}^{\circ} 59$, que tornou obrigatória a oferta da educação básica para todos os brasileiros. A Constituição Federal (CF) passou a vigorar com as seguintes alterações: "Art. 208. I - educação básica obrigatória e gratuita dos quatro (quatro) aos 17 (dezessete) anos de idade".

Em 2014, o Ministério da Educação (MEC) oficializou o novo Plano Nacional de Educação (PNE), que determina diretrizes, metas e estratégias para a política educacional brasileira nos próximos dez anos. E estabeleceu como meta $\mathrm{n}^{\circ} 1$ : universalizar, até 2016, a educação infantil na pré-escola para as crianças de 4 (quatro) a 5 (cinco) anos de idade e ampliar a oferta de educação infantil em creches, de forma a atender, no mínimo, $50 \%$ (cinquenta por cento) das crianças de até 3 (três) anos até o final da vigência deste PNE e, na meta 2: universalizar o ensino fundamental de 9 (nove) anos para toda a população de 6(seis) a 14 (quatorze) anos e garantir que pelo menos $95 \%$ (noventa e cinco por cento) dos alunos conclua essa etapa na idade recomendada, até o último ano de vigência deste PNE, outra vez assegurando o ingresso obrigatório da criança ainda na Primeira Infância no ensino fundamental.

2 E em 1998 foi homologado o Parecer do Conselho Nacional de Educação, que estabelecia as Diretrizes Curriculares para a Educação Infantil. 
Em 2014, a Rede Nacional Primeira Infância iniciou um forte movimento pela aprovação do Projeto de Lei $n^{\circ}$ 6.998/2013, de autoria do Deputado Osmar Terra e outros membros da Frente Parlamentar da Primeira Infância, que altera o art. $1^{\circ}$ e insere dispositivos sobre a Primeira Infância na Lei n ${ }^{\circ} 8.069$, de 13 de julho de 1990, que dispõe sobre o Estatuto da Criança e do Adolescente, sobre o Decreto Lei n 3.689, de 3 de outubro de 1941 - Código de Processo Penal; a Consolidação das Leis do Trabalho - CLT, aprovada pelo Decreto-Lei ${ }^{\circ}$ 5.452, de $1^{\circ}$ de maio de 1943; a Lei $n^{\circ} 11.770$, de 9 de setembro de 2008, que cria o Programa Empresa Cidadã, destinado à prorrogação da licença-maternidade mediante concessão de incentivo fiscal, e altera a Lei no 8.212, de 24 de julho de 1991 e a Lei ${ }^{\circ} 12.662$, de 5 de junho de 2012, que assegura validade nacional à Declaração de Nascido Vivo - DNV, regula sua expedição, altera a Lei no 6.015, de 31 de dezembro de 1973.

Em 2016, é sancionada a Lei n 13.257 , que criou o Marco Legal da Primeira Infância.

Em 2020, temos pela primeira vez na história uma proposta de plano orçamentário, que deixa absolutamente claro e inscrito o compromisso com a infância. A Comissão Mista de Planos, Orçamentos Públicos e Fiscalização do Congresso Nacional ofereceu um Parecer Preliminar ao Projeto de Lei do Plano Plurianual 2020-2023, destacando o Programa de Atenção Integral à Primeira Infância, apresentando meta ambiciosa, pois pretende ampliar o atendimento de crianças (da gestação até os 6 anos) dos atuais 357 mil beneficiários para 3 milhões até o final do ano de 2023.

Em que pesem todos os avanços, não se pode arrefecer a luta, para o atendimento educacional de aproximadamente vinte milhões de crianças de até seis anos, pois ainda somos uma sociedade profundamente desigual. Sem desmerecer todos os demais direitos sociais, inscritos na CF, como alimentação, moradia, transporte, saúde e assistência social, por exemplo, todos esses não se realizariam não fosse a educação, que cria as condições para que se possa usufruir plenamente de todos os direitos. Por tudo isto, insistimos na inclusão da educação entre os Direitos Fundamentais.

\section{O FUTURO EM 1000 DIAS}

Os primeiros anos, 1000 dias de vida de uma criança, são particularmente importantes. Os neurocientistas ressaltam que já durante a gestação há um movimento extraordinário de conexões neurais. Os mil dias são aqueles que vão da gestação humana, que dura cerca de 270 dias e somados aos dois primeiros anos de vida do bebê, cada ano com 365 dias, portanto, 730 
dias, constituem os primeiros 1000 dias de vida do bebê. Nesse período ocorrem trilhões de conexões no cérebro do bebê humano, atingindo o pico de sua atividade.

Os bebês aprendem nos primeiros anos como jamais aprenderão ao longo de toda a sua vida. Essa razão já seria suficiente para priorizar a Primeira Infância, se não tivéssemos outras tão importantes quanto esta.

$\mathrm{Na}$ fase de zero a dois anos, os estudiosos observaram um importantíssimo desenvolvimento cerebral. Cientistas informam que nos 1000 (mil) dias de vida o desenvolvimento cerebral é tão intenso que é possível estabelecer até 700 novas conexões neuronais por segundo, praticamente o dobro de sinapses executadas aos dez anos de idade, de acordo com estudos feitos pela Academia Nacional de Ciências dos Estados Unidos (2015).

O pediatra Jack P. Shonkoff ${ }^{3}$ (2016), do Centro de Desenvolvimento Infantil, da Universidade de Harvard, estudou um fenômeno chamado plasticidade cerebral, que ele descreveu como a capacidade do cérebro de ser flexível e adaptável e como ele pode reajustarse para assumir novos desafios. Jack Shonkoff (2016) afirma que o bebê ao nascer tem no cérebro todos esses neurônios, mas pouquíssimas conexões, pouquíssimos circuitos. Esses circuitos são rapidamente desenvolvidos nos primeiros anos de vida. "A plasticidade do cérebro está em níveis ótimos nos primeiros anos de vida da criança” (SHONKOFF, 2016, p. 98).

As causas para o desenvolvimento dessa plasticidade dependem da genética e do ambiente. Eles influenciam conjuntamente. Há uma série de predisposições e as experiências vividas por uma criança aproximam e potencializam essa extensão (SHONKOFF, 2016, p.97)

O cientista James Heckman, vencedor do Prêmio Nobel de Economia no ano 2000, realizou uma experiência de maior repercussão mundial para as políticas pela Primeira Infância. Foi o Projeto High Scope Perry Preschool que demonstrou com um estudo longitudinal, que acompanhou as crianças desde os 3 até os 41 anos de idade, que o investimento em programas de alta qualidade com respostas apropriadas às demandas das crianças resulta em um retorno de mais de 17 dólares por cada 1 dólar investido em programas sociais. Heckman expôs esse estudo em conferência realizada durante o I Seminário Internacional do Marco Legal da Primeira Infância, na Câmara dos Deputados, em 16 de abril de 2013.

James Heckman (2013), ao avaliar os dados sobre o desenvolvimento humano nos Estados Unidos, observou que a maneira mais eficiente de remediar problemas causados por ambientes familiares adversos é investir nas crianças em seus primeiros anos de vida. Para

\footnotetext{
${ }^{3}$ SHONKOFF, Jack. Professor de Pediatria na Faculdade de Medicina de Harvard e do Hospital Infantil de Boston Diretor do Centro da Criança em Desenvolvimento da Universidade de Harvard. Preside o Conselho Nacional Americano de Desenvolvimento Científico da Criança em Desenvolvimento.
} 
Heckman, os políticos devem ser sábios e levar em conta os resultados das ciências para fundamentá-las e devem ser bem planejadas para transferir capacidades. São incontestáveis os argumentos e evidências resultantes das pesquisas de diversas ciências que dão sustentação, bases fundamentais e diretrizes para a intervenção junto à primeira infância.

Ainda para o cientista, o investimento em políticas públicas para a primeira infância desde as idades mais precoces previne e melhora o estado de bem-estar e a abordagem das potencialidades do ser humano, tem impacto na redução das enfermidades crônicas das crianças pequenas, em suas habilidades sociais, cognitivas, emocionais e no rendimento e produtividade por toda sua vida (HECKMAN, 2013). ${ }^{4}$

Durante a conferência no I Seminário Internacional do Marco Legal da Primeira Infância, na Câmara dos Deputados, ele reiterou a relevância da participação dos pais no desenvolvimento pessoal das crianças, como de extrema importância dos mil primeiros dias de vida do ser humano, para desenvolver aprendizagens altamente significativas.

Em 21 de maio de 2019, James Heckman disse em uma entrevista à BBC que investir em educação para a primeira infância é a melhor 'estratégia anticrime'. A entrevista teve grande repercussão, uma vez que a BBC de Londres é uma emissora de TV e Rádio Pública, de muita credibilidade e alcance mundial. No Brasil, a entrevista ganhou repercussão no Jornal o Globo do dia 07/06/2019 e em outros órgãos de comunicação. O cientista destacou que o resultado anticrime é o principal do seu estudo. Para ele, o maior retorno para cada dólar investido em todos eles é a redução de crimes e a criação de um ambiente encorajador para as crianças.

\section{A DEMOCRACIA COMEÇA NO COLO DA MÃE}

Do momento em que uma nova vida é gerada até o momento em que a criança se incorpora ao convívio social, acontecem mudanças nas funções neurológicas, cognitivas e emocionais de relevância e intensidade impressionantes. É um período de crescimento intenso. Por isso, é fundamental entendermos como a biologia, a genética e a sociedade preparam essa nova vida, para viver e conviver no mundo.

Precisamos de um novo olhar sobre a primeira infância para entender, compreender, sentir e conviver com esse bebê humano. Certos cuidados com o novo ser são primordiais para o início da vida e determinantes do jeito dele ser e de existir no mundo.

\footnotetext{
4James Heckman em Conferência realizada durante o I Seminário Internacional do Marco Legal da Primeira Infância, na Câmara dos Deputados, em 16 de abril de 2013.
} 
Para o professor e filósofo Zejko Loparic (2020), um dos maiores estudiosos da obra de Donald Wood Winnicott ${ }^{5}$ (1896 a1971), o bebê humano nasce inacabado e precisa ser cuidado para integrar-se, temporalizar-se e personificar-se. Precisa sentir-se uno; aprender a mamar, falar e ter a ilusão de criação do seio da mãe; descobrir que ele existe independente da mãe; aprender a andar e a se relacionar com os outros, socializando-se, e ainda, precisa singularizarse. Por isto, o olho no olho; o abraço; o carinho e a conversa dos pais com o bebê, todas estas são atitudes simples que fortalecem todas as estruturas neurais da criança (LOPARIC, 2020).

Para o pediatra e psicanalista inglês Donald Winnicott $(1975$, p.96) tudo que uma criança precisa no início da vida é de uma "mãe suficientemente boa". E é nesse esforço de entender a psicologia do bebê, que Winnicott descobriu que o adoecimento do bebê era um fenômeno relacional, estava na relação mãe - bebê. Para ele, essas patologias são decorrentes das "falhas ambientais". Por exemplo, a mãe que não olha para o seu bebê ou que amamenta o bebê olhando para a televisão.

Para Winnicott (1975, p.96.), "as relações sociais começam no colo da mãe”. Essa relação mãe-bebê, se não for saudável, ou seja, se a mãe não for suficientemente boa, teremos crianças submissas que acatam os comandos da mãe, que não exercitam a sua criatividade, ou crianças que abstraem completamente o ambiente externo, se voltando para si, passando a se relacionar apenas com as suas fantasias interiores, podendo psicotizar.

Para Zeljko Loparic (2020), há casos de falhas ambientes muito mais graves que pode ter como consequência diferentes quadros psicopatológicos, dentre estes a psicose ${ }^{6}$. Ao falar de ambiente, nesta teoria, estaremos incluindo tanto o ambiente físico quanto os aspectos emocionais necessários ao desenvolvimento do bebê, representados por uma "mãe suficientemente boa" ou pessoa substituta, isto é, o começo da formação das relações pessoais.

O pediatra inglês buscava entender o adoecimento de bebês nos primeiros dias de vida: aquele bebê que não conseguia dormir; o bebê que ficava nervoso; que apresentava eczemas na pele; que chorava demais. E assim, começou a se dar conta de que a etiologia desses distúrbios pediátricos; distúrbios psicológicos; das patologias do bebê eram resultantes das relações entre bebês e suas mães. Mãe aqui, entendida como uma pessoa humana, não uma pessoa humana como objeto, segundo a psicanálise, mas a mãe/colo (LOPARIC, 2020).

\footnotetext{
${ }^{5}$ Donald Woods Winnicott foi um pediatra e psicanalista inglês. Para Winnicott, cada ser humano traz um potencial inato para amadurecer, para se integrar; porém, o fato de essa tendência ser inata não garante que ela vá ocorrer. Isto dependerá de um ambiente facilitador que forneça cuidados e esse ambiente é representado pela "mãe". Não necessariamente a própria mãe do bebê, mas aquela que efetua uma adaptação ativa às necessidades do bebê.

${ }^{6}$ Donald W. Winnicott, O brincar e a Realidade, 1975, P.96.
} 
O filósofo Luiz Felipe Pondé (2020) pergunta a Loparic ${ }^{7}$ : O que Winnicott ensina de novo em relação à tradição freudiana? E Loparic respondeu "Winnicott concebia que as relações sociais começam no colo da mãe".

No começo tudo que o bebê precisa é do colo da mãe (WINNICOTT, 1975). Ao falar de ambiente, nesta teoria, estaremos incluindo tanto o ambiente físico quanto os aspectos emocionais necessários ao desenvolvimento do bebê, representados por uma "mãe suficientemente boa". Depois dessa fase de integração, precisamos da mãe que cumpre a função de personificação, trocando a frauda, expondo o bebê à luz, fazendo-lhe experimentar a audição das vozes das pessoas, tocando em cada uma das partes do corpo da criança, permitindo a formação pelo bebê da sua imagem corporal etc. Todas essas experiências sensoriais são importantes para formação da personificação.

Também é fundamental que a mãe apresente os objetos ao bebê, sendo o seio o primeiro deles e objeto de satisfação que permite ao bebê o exercício da onipotência da ilusão de tê-lo criado. E, ainda, é o começo da formação das relações pessoais. Também chama-nos a atenção para uma aprendizagem muito necessária que o bebê realiza na relação com a mãe para as relações futuras, lidando com a ambivalência: amor e ódio (WINICOTT, 1975).

Para Loparic (2020), maturidade é sinônimo de saúde; uma pessoa saudável é matura, significa capacidade de tolerar o amor e ódio com outra pessoa ou com outro grupo social e ressalta que, embora Winnicott tenha tomado de Freud a abordagem das relações humanas, compreendia que o bebê está no colo da mãe para existir, não por uma questão sexual; ele precisa do ambiente para existir; para existir como uma unidade pessoal; como alguém que precisa se relacionar com o ambiente e com o mundo a sua volta; entrar no mundo familiar, escolar, na sociedade.

Desses cuidados iniciais dos bebês dependem as suas capacidades de se concentrarem e deslocarem a sua atenção, de administrarem os sentimentos, controlarem os impulsos, seguirem regras e orientações, de se adaptarem a uma série de demandas, mas principalmente confiarem no ambiente, em si, no outro, no ambiente.

Então, a democracia se assenta nas capacidades adquiridas no colo da mãe e na relação com a família. A democracia, no fundo, depende das aquisições do bebê humano no colo da mãe, na família e na escola.

\footnotetext{
${ }^{7}$ No canal Democracia na Teia, o filósofo Felipe Pondé (2020) entrevistou o filósofo Zeljko Loparic que é professor da Unicampi e destacado estudioso da obra de Donald Winnicott no Brasil, tendo relevantes contribuições em outros países, especialmente na China.
} 
Perguntado por Felipe Pondé se democracia para o winnicottiano é uma questão de saúde psíquica, Loparic (2020) responde que sim. Numa situação de conflito social, uma pessoa saudável vai se colocar de um lado ou do outro, sem que isso signifique a exclusão do outro lado; a satanização; o aniquilamento do outro ou do grupo social. Portanto, para os teóricos winnicotianos, "a democracia começa no colo da mãe".

\section{CONCLUSÕES}

O país começa a se beneficiar de conhecimentos científicos e a colher os seus frutos, com a criação de leis e aplicações nas políticas pela primeira infância. As recentes descobertas científicas sobre o desenvolvimento intenso do cérebro humano na Primeira Infância, associadas aos argumentos econômicos e sociais, tornam incontestáveis à necessidade de alçar a educação infantil como um direito fundamental, comparando-o ao direito à vida. Deve-se destacar que todas as razões sobre as quais discorremos guardam profunda relação com a necessidade de superação da desigualdade social, ou seja, promover a igualdade ao nascer.

Para além da diferença de classe, a raiz da desigualdade social se realiza na diferença de cuidados e educação ao nascer. As razões para investirmos nas políticas pela Primeira Infância são muitas e algumas mais disseminadas, como: as experiências nesta fase da vida são persistentes e duradouras, com impacto para toda a vida; há elevada capacidade e plasticidade do cérebro em formação das funções cognitivas e demais funções; há nessa fase ausência de conflitos entre meritocracia e igualdade de oportunidades, o que nivela os pontos de partida e dá igualdade de oportunidades; todas as crianças são similarmente talentosas na Primeira Infância; os investimentos iniciais são duradouros, influenciando o ciclo de vida total.

É preciso um esforço gigantesco para unir todas as forças dos governos, das instituições educacionais, pais e professores; especialistas da área da saúde; da assistência social e da psicologia; profissionais de arte, da cultura e esporte, com o objetivo de prevenir e buscar solução para a banalização da vida, dedicando tempo, energia, conhecimento e muito amor pela Primeira Infância.

\section{REFERÊNCIAS}

ACADEMIA NACIONAL DE CIÊNCIAS DOS ESTADOS UNIDOS. In: Bibiano, Bianca. Por que investir na Primeira Infância pode mudar o Brasil. Revista Veja, 2015. Disponível em: http://veja.abril.com.br/noticia/educacao/por-que-investir-na-primeira-infancia-pode-mudar-obrasil. Acesso em: mar. de 2010 
AZEVEDO, Fernando de et al. Manifesto dos Pioneiros da Educação Nova (1932) e dos Educadores (1959). Fundação Joaquim Nabuco, Recife: Editora Massangana, 2010.

BERNARDI, Iara; ROCHA, Maria José. Educação Infantil: um direito fundamental. In: Marco Legal da Primeira Infância. Centro de Estudos e Debates Estratégicos - Cedes. Câmara dos Deputados, Brasília, 2016.

BRASIL. PARECER CNE/CEB 22/1998 - Homologado em 22/3/1999, publicado no Diário Oficial da União de 23/3/1999, Seção 1, p. 8.

Resolução CNE/CEB 1/1999, publicada no Diário Oficial da União de 13/4/1999, Seção 1, p. 18.

SANTOS, Daniel D.; PORTO, Juliana A.; LERNER, Rogério. O Impacto do Desenvolvimento na Primeira Infância sobre a Aprendizagem. 2. ed. São Paulo: Fundação Maria Cecília Souto Vidigal, 2015.

WINNICOTT, Donald Woods. O Brincar e a Realidade. Imago Editora: Rio de Janeiro, 1975. 